The submitted manuscript has been created by UChicago Argonne, LLC, Operator of Argonne National Laboratory ("Argonne"). Argonne, a U.S. Department of Energy Office of Science laboratory, is operated under Contract No. DEAC02-06CH11357. The U.S. Government retains for itself, and others acting on its behalf, a paid-up nonexclusive, irrevocable worldwide license in said article to reproduce, prepare derivative works, distribute copies to the public, and perform publicly and display publicly, by or on behalf of the Government.

(C) 2016. This manuscript version is made available under the Elsevier user license http://www.elsevier.com/open-access/userlicense/1.0/ 


\title{
Load-Partitioning in an Oxide Dispersion-Strengthened 310 Steel at Elevated Temperatures
}

\author{
Yinbin Miao ${ }^{\mathrm{a}, \mathrm{b}, *}$, Kun $\mathrm{Mo}^{\mathrm{a}}$, Zhangjian Zhou ${ }^{\mathrm{c}}$, Xiang Liu ${ }^{\mathrm{b}}$, Kuan-Che Lan ${ }^{\mathrm{b}}$, Guangming \\ Zhang ${ }^{\mathrm{b}, \mathrm{c}}$, Jun-Sang Park ${ }^{\mathrm{a}}$, Jonathan Almer ${ }^{\mathrm{a}}$, James F. Stubbins ${ }^{\mathrm{b}, \mathrm{d}}$ \\ ${ }^{a}$ Argonne National Laboratory, Lemont, IL 60439, United States \\ ${ }^{b}$ University of Illinois at Urbana-Champaign, Urbana, IL 61801, United States \\ ${ }^{c}$ University of Science and Technology Beijing, Beijing, 100082, China \\ ${ }^{d}$ International Institute for Carbon-Neutral Energy Research (I2CNER), Kyushu University, Fukuoka 819-0395, Japan
}

\begin{abstract}
Here the high temperature tensile performance of an oxide dispersion-strengthened (ODS) 310 steel is reported upon. The microstructure of the steel was examined through both transmission electron microscopy (TEM) and synchrotron scattering. In situ synchrotron X-ray tensile investigation was performed at a variety of temperatures, from room temperature up to $800^{\circ} \mathrm{C}$. Pyrochlore structure yttrium titanate and sodium chloride structure titanium nitride phases were identified in the steel along with an austenite matrix and marginal residual $\alpha^{\prime}$-martensite. The inclusion phases strengthen the steel by taking extra load through particle-dislocation interaction during plastic deformation or dislocation creep procedures. As temperature rises, lattice strain measurement implies that the load partitioning effect of conventional precipitate phases starts to diminish, whereas those ultra-fine oxygen-enriched nanoparticles continue to maintain a considerable amount of extra lattice strain. Introduction of oxygen-enriched nanoparticles in austenitic steel provesis shown to improve the high temperature performance, making austenitic ODS steels promising for advanced nuclear applications.
\end{abstract}

Keywords: oxide dispersion strengthened (ODS) alloy, austenitic steel, synchrotron scattering, high-resolution transmission electron microscopy (HRTEM), in situ tensile investigation

*Tel: +1 (630)252-7448. Email: ymiao@anl.gov (Y. Miao) 


\section{Introduction}

Advanced nuclear fission reactors and prospective fusion conceptions involve an extreme in-core environment and bring out tough material challenges for the nuclear industry[1]. Mechanical alloying is capable of introducing a dense and dispersed distribution of ultra-fine oxygen-enriched nanoparticles into steel matrices in order to produce oxide dispersion-strengthened (ODS) steels[2, 3]. These nanoparticles can not only pin dislocations to inhibit plastic deformation and dislocation creep[4], but also trap irradiation-induced defects to suppress radiation damage evolution and consequent degradation of material performance[5,6]. Therefore, ODS steels are regarded as promising candidates for structural materials in future nuclear systems[7].

Due to their intrinsic advantages in mechanical strength and radiation resistance, ferritic/martensitic (F/M) ODS steels have been frequently studied for potential applications in fission reactor pressure vessels (RPVs) or fusion reactor first walls (FWs)[8, 4, 9]. Meanwhile, with high-temperature phase stability, austenitic steels also have exceptional corrosion and creep resistance. Combined with enhanced mechanical strength and radiation tolerance originating from the ultra-fine nanoparticles, austenitic ODS steels are expected to qualify for in-core structural materials of advanced reactors, such as fuel cladding for supercritical water reactors. Thus, austenitic ODS steels have been developed and investigated in order to explore their prospective use in nuclear industry[10, 11, $12,13,14,15]$

As part of the long search for austenitic ODS steels that are practical for advanced nuclear designs, an ODS 310 stainless steel was developed and investigated in this study. As the origin of the outstanding properties of ODS steels, the microstructural characteristics of the ultra-fine oxygen-enriched nanoparticles determine the macroscopic performance. Hence, it is important to examine the microstructure of this ODS 310 steel, especially the properties of these nanoparticles and their responses to externally applied stress. This task calls for a combined utilization of advanced materials characterization techniques. The diffraction contrast imaging of transmission electron microscopy (TEM) is capable of revealing the number density and size distribution of nanoparticles, whereas the high-resolution transmission electron microscopy (HRTEM) can capture the crystal structure of nanoparticles along with their orientation relationship with the 
austenite matrix. Additionally, having extraordinary beam energy and intensity, synchrotron radiation is an ideal tool to characterize inclusion phases that have marginal volume fractions[16, $17,18]$ such as oxygen-enriched nanoparticles. In fact, synchrotron-based techniques have already been successfully applied to the characterization of ODS steels in the past few years[9, $19,20,21]$.

In this study, the oxygen-enriched nanoparticles in a recently developed ODS 310 stainless steel were first $e x$ situ investigated by both TEM and synchrotron X-ray scattering. Then in situ synchrotron tensile tests were conducted within a wide range of temperatures from room temperature, through the operation temperature of fuel cladding materials in light water reactors $\left(350^{\circ} \mathrm{C}\right)$ and supercritical water reactors $\left(500^{\circ} \mathrm{C}\right)$, up to those extreme temperatures usually found in accidental scenarios $\left(650^{\circ} \mathrm{C}\right.$ and $\left.800^{\circ} \mathrm{C}\right)$, so that the responses of those nanoparticles to externally applied stress could be comprehensively studied to evaluate the qualification of austenitic ODS steels for advanced nuclear applications.

\section{Experiments}

The ODS 310 steel investigated in this study has the nominal composition as listed in Table 1. The base material powders were first mechanically alloyed in an inert atmosphere using a planetary ball mill at $300 \mathrm{rpm}$ with a ball-to-powder ratio of 5:1 for 30 hours. The milled powders were then degassed, sealed, and consolidated through hot isostatic pressing (HIP) under a pressure of $100 \mathrm{MPa}$ at $1150^{\circ} \mathrm{C}$ for 3 hours. A similar manufacturing procedure has been used to produce a series of $\mathrm{F} / \mathrm{M}$ and austenitic ODS steels with excellent performance.

Table 1: Nominal compositions of investigated ODS steels (wt $\%$ )

\begin{tabular}{ccccccc}
\hline Material & $\mathrm{Fe}$ & $\mathrm{Cr}$ & $\mathrm{Ni}$ & $\mathrm{Mo}$ & $\mathrm{Ti}$ & $\mathrm{Y}_{2} \mathrm{O}_{3}$ \\
\hline ODS310 & bal. & 24.0 & 18.3 & 1.9 & 0.3 & 0.35 \\
\hline
\end{tabular}

In order to prepare specimens suitable for TEM observation, $3 \mathrm{~mm}$ discs with a thickness of approximately $250 \mu \mathrm{m}$ were cut from the bulk material using electric discharge machining (EDM). These discs were first mechanically thinned and polished to a $100 \mu \mathrm{m}$ thickness and 
a $0.05 \mu \mathrm{m}$ surface finish by sandpapers and diamond suspensions. The specimens were then electropolished to electron transparency for TEM observation using a solution containing 5 vol.\% perchloric acid and $95 \mathrm{vol} . \%$ methanol at $-14^{\circ} \mathrm{C}$. Both diffraction contrast imaging and HRTEM investigations were performed on a JEOL $2010 \mathrm{LaB}_{6}$ TEM with a $200 \mathrm{kV}$ electron beam.

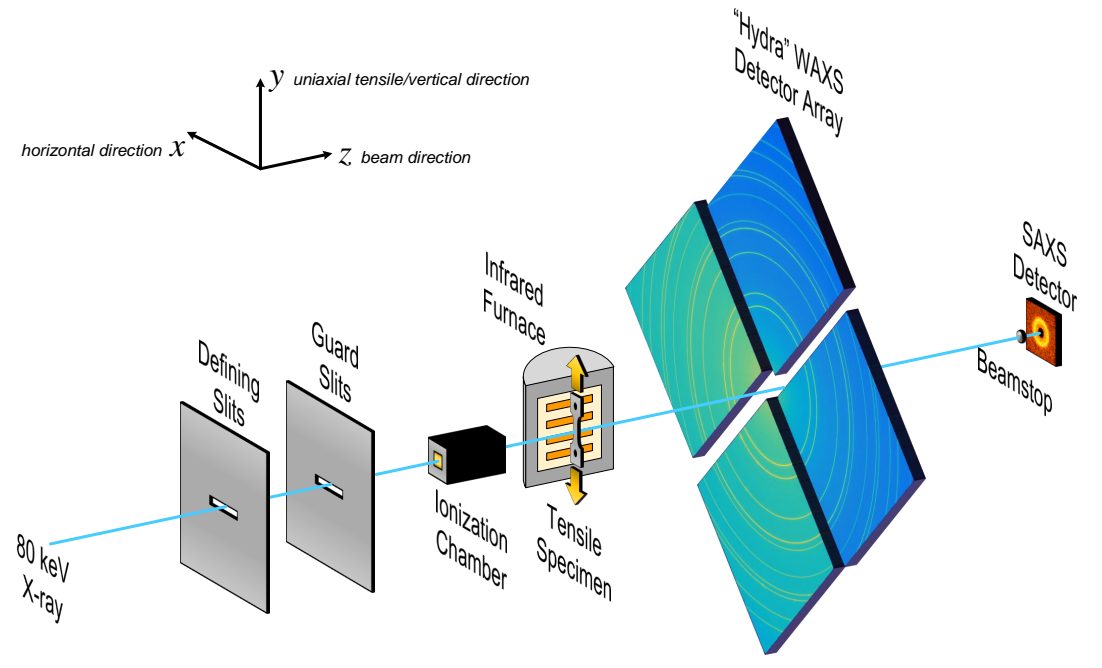

Figure 1: Synchrotron experiment setup

Synchrotron involved investigations were performed at Sector 1-ID, Advanced Photon Source (APS), Argonne National Laboratory (ANL). An $80.7 \mathrm{keV} \mathrm{(} \lambda=0.154 \AA$ ) monochromatic synchrotron beam was used to illuminate the specimens to generate scattering signals. Four GE-RT41 detectors, each of which contains $2048 \times 2048$ pixels, were combined to form the HYDRA detector array to collect wide angle X-ray scattering (WAXS) signals. Meanwhile, a Scint-X detector was used to capture small-angle X-ray scattering (SAXS) information. The ODS 310 steel was also cut into miniature tensile specimens with gauge sections of $1.20 \mathrm{~mm}$ (width) $\times 0.5 \mathrm{~mm}$ (thickness) $\times 5.00$ $\mathrm{mm}$ (length) by EDM. The tensile specimens were mounted on an MTS tensile stage with an infrared clamshell furnace for in situ synchrotron tensile investigation. The tensile tests were performed using a $2 \times 10^{-4} \mathrm{~s}^{-1}$ strain rate at room and elevated temperatures up to $800^{\circ} \mathrm{C}$. Each synchrotron WAXS exposure took 4 seconds. The fracture surface of each strained specimen was investigated by a JEOL IT-100 scanning electron microscope (SEM). 
The $10^{\circ}$ regions of the Debye-Scherrer diffraction rings near the uniaxial tensile direction were integrated to provide the lattice spacings evolution during straining. The lattice strains were also calculated accordingly, $\varepsilon_{22}^{h k l}=\left(d^{h k l}-d_{0}^{h k l}\right) / d_{0}^{h k l}$, where, $h k l$ is the Miller'sMiller index of the measured diffraction ring, $d^{h k l}$ is the measured lattice spacing between two neighboring $\{\mathrm{hkl}\}$ planes, $d_{0}^{h k l}$ is the measured lattice spacing of the unloaded specimen at the testing temperature. Likewise, the lattice strain at the horizontal direction, $\varepsilon_{11}$, can also be deduced-aecordingly. $\varepsilon_{33}$ was assumed to be equal to $\varepsilon_{11}$. For the austenite matrix, the average bulk lattice strain was derived from the lattice strains of $\{111\},\{200\},\{220\},\{311\},\{222\},\{400\}$, and $\{331\}$ reflections using the weighted averaging algorithm developed by Daymond[22] and successfully applied by Miao et al. to austenitic ODS steels[14]. The temperature-dependent elastic stiffness tensor of 316 stainless steel [23] was adopted in this study due to the similarity of elastic moduli among austenitic steels and the lack of related data for 310 stainless steels.

Aside from the lattice strain, diffraction peaks also contain information about dislocation density, stacking fault portion (for FCC structured-materials), and grain size of the samples. The modified Williamson-Hall (W-H) analysis was used to interpret this information from the broadening of diffraction peaks. In the modified W-H analysis, the peak broadening is governed by the following equation:

$$
\Delta K=\left(\frac{1.5 \alpha+\beta}{a}\right) W(g)+\frac{0.9}{D}+\left(\frac{\pi A^{2} b^{2}}{2}\right)^{\frac{1}{2}} \rho^{\frac{1}{2}}\left(K \bar{C}^{\frac{1}{2}}\right)
$$

where, $\alpha$ is the stacking fault portion, $\beta$ is the twinning portion, $a$ is the lattice constant, $W(g)$ is a reflection-dependent parameter given in Ref. [24], $D$ is the average grain size, $A$ is an adjustable coefficient that was selected to be 1 for dislocation density around $10^{14} \mathrm{~m}^{-2}$ level, $b$ is the Burgers vector of the slip system, $\rho$ is the dislocation density, $\bar{C}$ is the contrast factor that will be discussed in detail later, $K=2 \sin \theta / \lambda, \Delta K=2 \cos \theta d \theta / \lambda, \theta$ is the diffraction angle, and $\Delta \theta$ is the breadth of the diffraction peak. The breadths of the diffraction peaks were derived by fitting diffraction peaks to pseudo-Voigt functions. The contrast factor is dependent on the elastic stiffness of the material. The details of deduction of $\Delta \theta$ and $\bar{C}$ of austenite phase can be found in Ref. [25]. Meanwhile, the SAXS data were analyzed by the Irena package[26] using a unified 
sphere model[27] and maximum entropy optimization algorithm[28, 29].

\section{Results and Discussions}

Due to the existence of these oxygen-enriched nanoparticles, the grain growth during manufacturing is inhibited. As shown by the TEM bright field image (see Figure 2(a)), the average grain size is approximately $300 \mathrm{~nm}$. The bright field image with higher magnification shows the dense and dispersed distribution of ultra-fine oxygen-enriched nanoparticles (see Figure 2(b)). By analyzing the bright field TEM images, the size distribution was measured for these nanoparticles and is showed in Figure 2(c). Although the volume fraction distribution is bimodal, the majority of these nanoparticles were found to be smaller than $10 \mathrm{~nm}$ in diameter with a mean diameter of $4.6 \pm 0.3 \mathrm{~nm}$. In addition to those ultra-fine nanoparticles, large oxide nanoparticles with tens of nm in diameter are also scarcely distributed within the material, as shownillustrated in Figure 2(b)(d). It is also worth mentioning that the measured fractions of nanoparticles larger than 16 $\mathrm{nm}$ have considerable errors due to the limited number of large nanoparticles that were observed in TEM images.

Further TEM investigation using the HRTEM technique indicates the electron diffraction information of these nanoparticles, which can be used to determine their crystal structures. The nanoparticles were found to have a pyrochlore structure, implying a $\mathrm{Y}_{2} \mathrm{Ti}_{2} \mathrm{O}_{7}$ stoichiometry. In fact, it was recently found[30] that the Ti ions in $\mathrm{Y}_{2} \mathrm{Ti}_{2} \mathrm{O}_{7}$ can be replaced by $\mathrm{Y}$ ions through the O-vacancy compensation mechanism[31], giving a $\mathrm{Y}_{2} \mathrm{Ti}_{2-x} \mathrm{O}_{7-2 x}(0 \leq x \leq 1)$ stoichiometry and maintaining a defective pyrochlore structure. This finding was also confirmed by the observation of the $\mathrm{Y}_{2} \mathrm{Ti}_{2-x} \mathrm{O}_{7-2 x}$ nanoparticles in austenitic ODS steels[15]. For the sake of simplicity, $\mathrm{Y}_{2} \mathrm{Ti}_{2} \mathrm{O}_{7}$ will be used hereafter to represent those oxide nanoparticles. By comparing the electron diffraction of the nanoparticles with that of the austenite matrix, a cubic-on-cubic $(\mathrm{CoC})$ orientation relationship was found between the nanoparticles and the matrix, as indicated by Figure 3 . Both the crystal structure and orientation relationship findings in this study are consistent with what were reported in other austenitic ODS steels $[14,15]$. It is worth mentioning that the $\mathrm{CoC}$ orientation relationship is also semi-coherent. Thus, the coherency strain contributes to the 

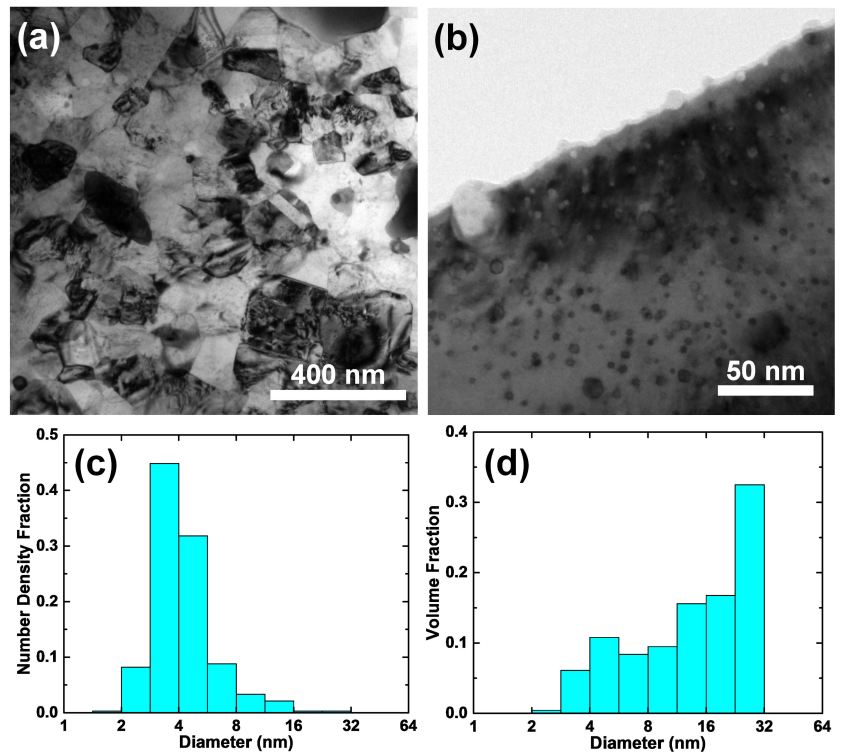

Figure 2: Bright-field TEM images of the ODS 310 steel: (a) a low-magnification image showing an approximately 200 $\mathrm{nm}$ grain size of the ODS 310 steel; (b) a high-magnification image showing the dense and dispersed distribution of oxygen-enriched nanoparticles; (c)/(d) size distribution of oxygen-enriched nanoparticles.

thermal misfit strain, which is included in the diffraction-measured atomic spacing, $d_{0}^{h k l}$.
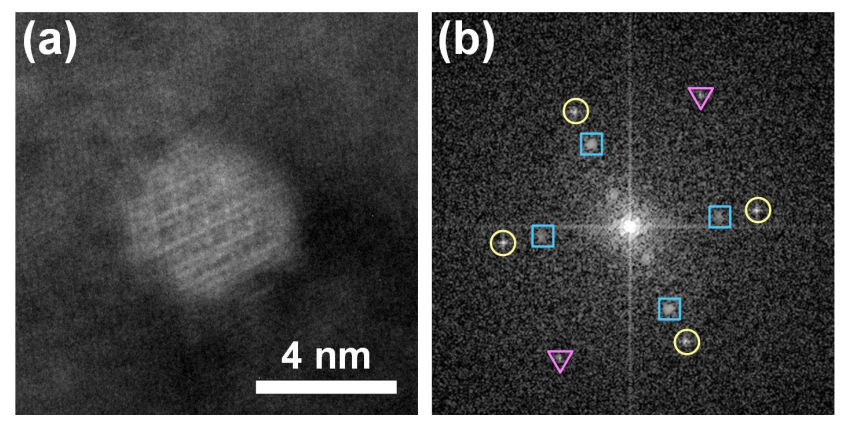

Figure 3: HRTEM analysis of an ultra-fine nanoparticle $(\mathrm{d}=4 \mathrm{~nm})$ : (a) HRTEM image showing the atom columns of both the austenite matrix and oxygen-enriched nanoparticle; (b) the FFT image of (a), showing the diffraction patterns of austenite phase (yellow circles for $\{111\}$, and pink triangles for $\{200\}$ ) and nanoparticle phase (blue squares for $\{222\}$ ).

In order to identify all the phases in the ODS 310 steel, the WAXS data were carefully analyzed. The line-out diffraction data were obtained by integrating the 2-D WAXS signals collected by the HYDRA detector array (see Figure 4). Aside from the austenite matrix and 
the pyrochlore nanoparticle phase that has already been identified by electron diffraction, a TiN phase with a $\mathrm{NaCl}$ structure (a conventional $\mathrm{MX}$ precipitate phase in austenite) and marginal amount of residual $\alpha^{\prime}$-martensite was also found in ODS 310 steel. The nitrogen that formed TiN came from the inert atmosphere used during mechanical alloying. In TEM images, those TiN precipitates are usually larger than approximately $100 \mathrm{~nm}$, and therefore, can be distinguished from oxygen-enriched nanoparticles.

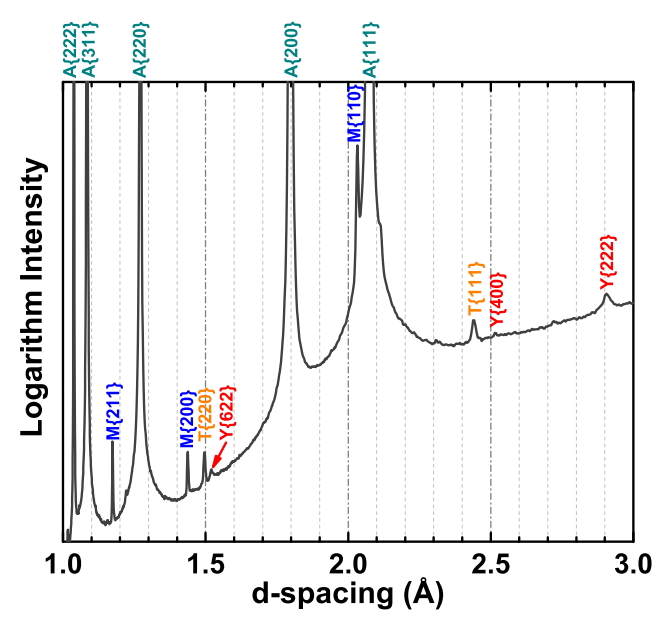

Figure 4: Diffraction peaks of distinguishable phases corresponding to d-spacings ranging from 1 to $3 \AA$ : "A" stands for austenite; "M" stands for martensite; "T" stands for titanium nitride; and "Y" stands for yttrium titanate.

The SAXS signal of the ODS 310 steel (see Figure 5(a)) also includes the size distribution information of the ultra-fine precipitate phases. After fitting to the unified sphere model, the size distribution (volume density) indicates the existence of multiple peaks. The first peak (near $10 \mathrm{~nm}$ in diameter) corresponds to the ultra-fine nanoparticles investigated by TEM as discussed before. The second peak (near $30 \mathrm{~nm}$ ) accounts for those large and scarce oxide nanoparticles. The size distribution derived from the SAXS data is comparable with the TEM observation (see Figure 2(d)). As the SAXS investigation involved a larger illuminated volume, the consistency of those two characterization techniques also demonstrate that the TEM observation of the nanoparticles are representative.

The strain-stress curves of ODS 310 strained at a variety of temperatures are illustrated in 

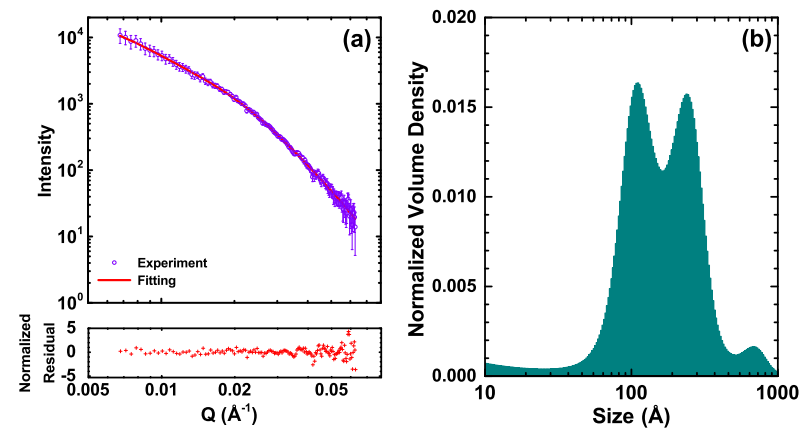

Figure 5: Precipitates characterization based on SAXS: (a) integrated SAXS data and the corresponding sphere model fitting curve; (b) SAXS-deduced size distribution of the precipitates in the ODS 310 steel.

Figure 6. At all these temperatures ODS 310 shows excellence in yield stress and ultimate tensile strengths with considerableacceptable ductility. A more detailed comparison can be found in Figure 7. As the temperature rises, the strength of ODS 310 continues to decrease. Meanwhile, the elongation of ODS 310 has a local minimum at $350^{\circ} \mathrm{C}$. This phenomenon is known as the minimum ductility phenomenon or ductility-dip that is common for austenitic stainless steels and Ni-based alloys[32, 33]. As the temperature where the ductility dip occurs is positively dependent on grain size[34], in the ODS 310 steel the reduced grain size results in an extraordinarily low dip temperature compared to non-ODS austenitic stainless steels. Additionally, in comparisom to conventional 310 stainless steel, ODS 310 provides superior mechanical strength with acceptable compromise in elongation.

Precipitates help suppress plastic deformation or dislocation creep by pinning dislocations. Through this precipitate-dislocation interaction, precipitates actually take extra load compared to the matrix, resulting in the partitioning of load between phases. This difference in stress can be measured by investigating the lattice spacings of each phase through synchrotron X-ray diffraction. The lattice strain evolution of all the analyzable phases, including the austenite matrix, TiN, and $\mathrm{Y}_{2} \mathrm{Ti}_{2} \mathrm{O}_{7}$, within ODS 310 during the room temperature tensile test is illustrated in Figure 8(a). The limited amount of the residual $\alpha$ '-martensite provide inadequate illuminated volume for statistical synchrotron analysis. Therefore, only the austenite matrix along with 


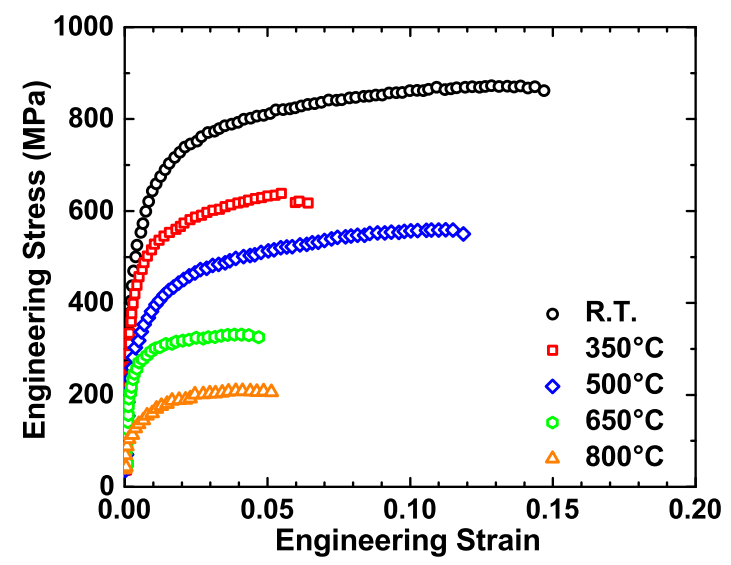

Figure 6: Tensile curves of ODS 310 steel at various temperatures up to $800^{\circ} \mathrm{C}$. The ductility dip phenomenon of austenitic stainless steels occurs near $350^{\circ} \mathrm{C}$.
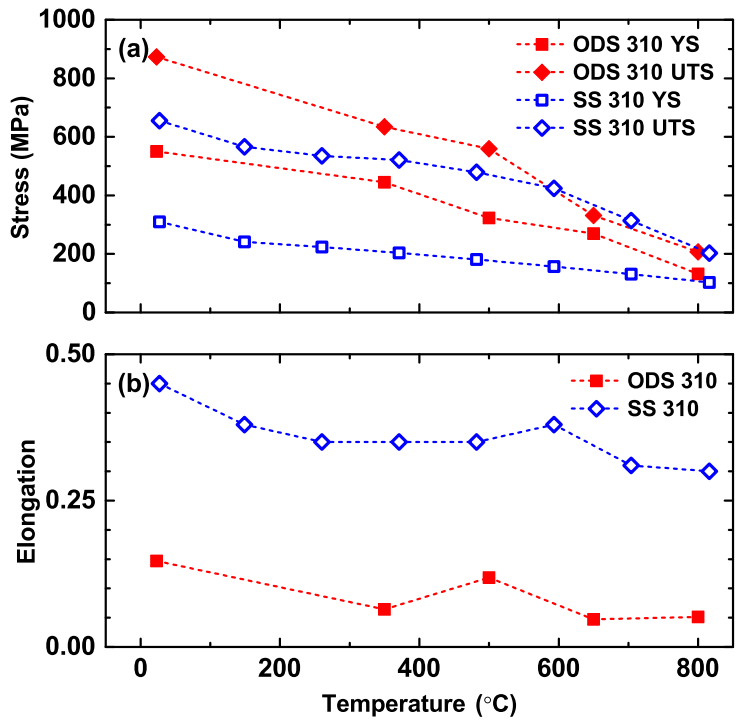

Figure 7: Tensile properties of ODS 310 steel at various temperatures up to $800^{\circ} \mathrm{C}$, in comparison with conventional 310 stainless steel[35]: (a) yield stress (YS) and ultimate tensile strength (UTS) of ODS 310; (b) tensile elongation of ODS 310 . 
TiN and yttrium titanate precipitates were studied in this work. Based on the intensities of corresponding diffraction peaks, the volume fractions of the nitride and oxide phases were determined to be respectively $0.73 \pm 0.13 \%$ and $0.77 \pm 0.19 \%$ using the method introduced in Ref. [14]. The scatter of the measured lattice strains of the two precipitate phases areis apparently larger than that of the matrix phase. This is mainly associated with the statistical error originating from the limited volume fractions of the precipitate phases. For the oxide nanoparticles, the scatter is even larger due to the local fluctuation of the average stoichiometry parameter, $\mathrm{x}$, as in the formular $\mathrm{Y}_{2} \mathrm{Ti}_{2-x} \mathrm{O}_{7-2 x}$. To better analyze the load partitioning effect, the lattice stresses, $\sigma_{22}$, of all three phases were derived from $\varepsilon_{11}$ and $\varepsilon_{22}$ measured by the WAXS data, as shown in Figure 8(b). For the two precipitate phases, their elastic moduli and Poisson ratios were directly derived from the single-crystal elastic stiffness tensors based on the Reuss model $\left(E_{T\{111\}}=337\right.$ $\mathrm{GPa}, v_{T\{111\}}=0.282[36], E_{Y\{222\}}=261 \mathrm{GPa}$, and $v_{Y\{222\}}=0.245$ [37]). For the austenite matrix, the lattice stress was calculated using the average lattice strain and average Young's modulus based on the room temperature single-crystal elastic stiffness[23] and the Harris texture index[38] evolution during the tensile test, as described by Daymond et al[22]. It is obvious that the two precipitate phases take more stress compared to the matrix phase. In fact, the difference between the true stress and the austenite's lattice stress is mainly contributed by that extra stress taken by precipitates. Also, the nanoparticle phase, $\mathrm{Y}_{2} \mathrm{Ti}_{2} \mathrm{O}_{7}$, was found to take slightly higher load than the conventional MX strengthening phase does.

As temperature increases, the load partitioning phenomenon evolves. Due to the lack of credible elastic constants of the precipitate phases (the oxide phase in particular) at elevated temperature, only the lattice strains were compared to provide semi-quantitaive information. The extra lattice strain of the TiN phase continues to drop with the increasing temperature. As temperature exceeds $500^{\circ} \mathrm{C}$, the lattice strain of $\mathrm{TiN}$ becomes even lower than that of the matrix. As a ceramic phase, TiN should have higher Young's modulus than the alloy matrix so that the TiN precipitates may still take extra load in that case. However, the rapid and apparent drop of its lattice strain implies severe degradation of the load partitioning phenomenon of TiN at high temperatures. On the other hand, the $\mathrm{Y}_{2} \mathrm{Ti}_{2} \mathrm{O}_{7}$ phase retains a prominent extra lattice strain at all 

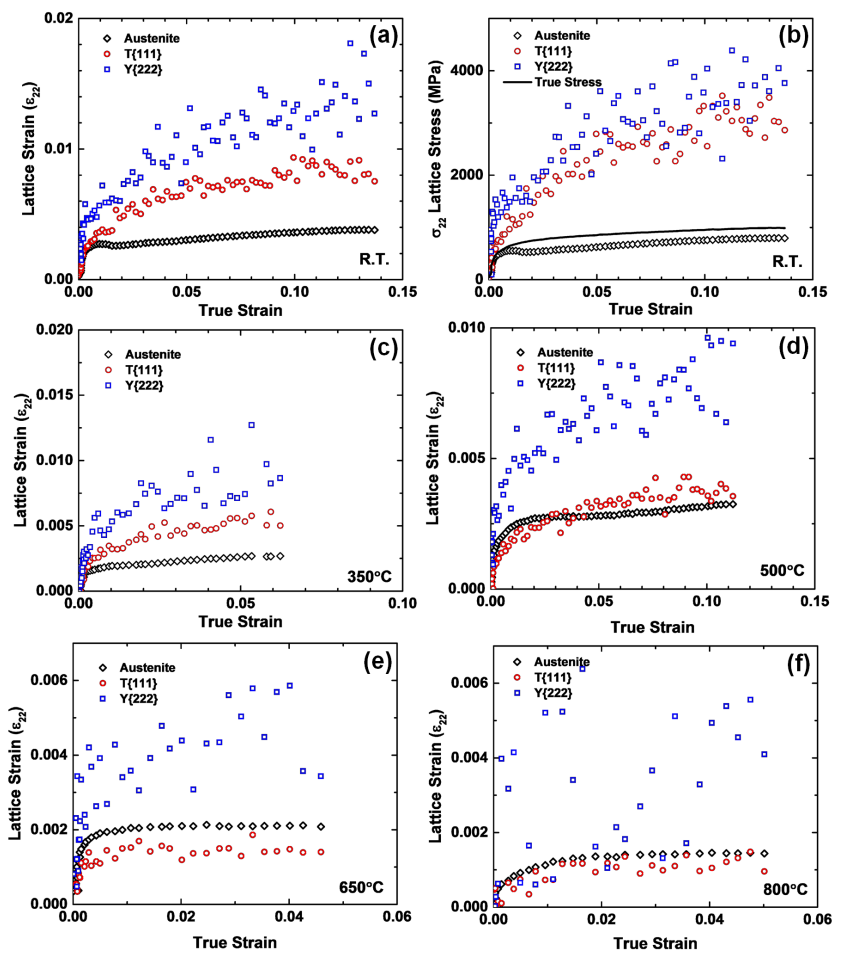

Figure 8: Load partition phenomenon investigated by synchrotron WAXS: (a), (c) through (e) lattice strain evolution during tensile tests at various temperatures; (b) lattice stress evolution during the room temperature tensile investigation. 
temperatures involved in this study. This observation indicates that the ultra-fine nanoparticles play an indispensable role in maintaining excellent mechanical strength at elevated temperatures. Namely, it is clear that the ODS technique is essential for improving the performance of austenitic steels at high temperatures for advanced nuclear applications.

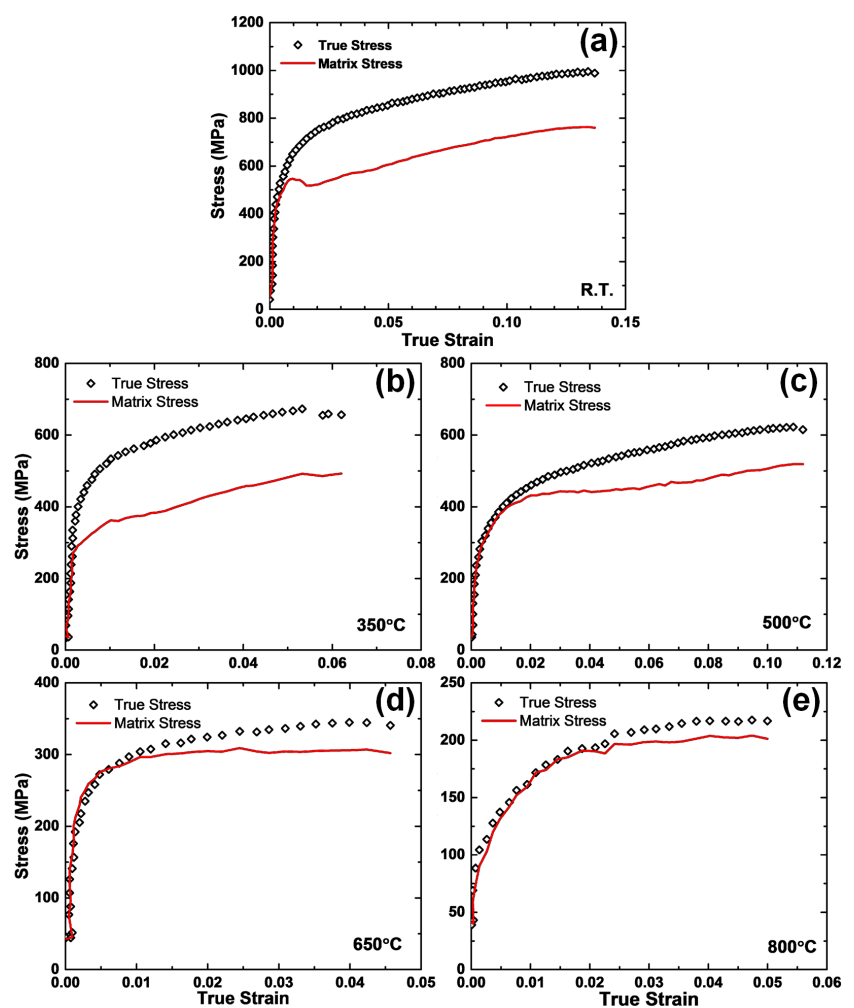

Figure 9: Comparison between lattice stress of austenite matrix and true stress at various temperatures.

An alternative way to look into the contributions of the precipitate phases to mechanical strength is through comparing the true stress with the average lattice stress of the matrix during tensile tests[35], as shown in Figure 9. The lattice stress deduction followed the method used in Figure 8(b) with temperature-dependent single-crystal elastic stiffness[23]. At room temperature, up to a quarter of the true stress comes directly from precipitate phases. This ratio continues to drop as temperature exceeds $500^{\circ} \mathrm{C}$. At $800^{\circ} \mathrm{C}$, only approximately one tenth of the true stress is due to the load partitioning effect. This decrease can be explained by the fading of the load 
partitioning of TiN precipitates. Again, the ultra-fine oxygen-enriched nanoparticles maintain their capability of bearing extra stress at elevated temperatures, contributing to the strengthening of the alloy. Additionally, as nanoparticles stop dislocation movement and result in the formation of dislocation pile-ups, the dislocation density in strained ODS steels is higher than that of conventional steels. This high dislocation density also promotes the effect of work hardening, further contributing to the enhancement of the mechanical strength.

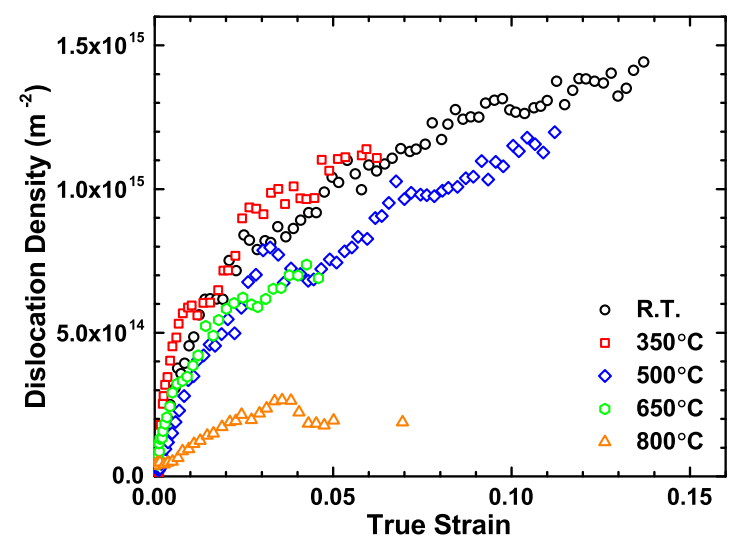

Figure 10: Evolution of dislocation density in the ODS 310 steel strained at different temperatures

Dislocation density evolution during the tensile tests was deduced based on the modified Williamson-Hall fitting of the diffraction peak broadening. The results are shown in Figure 10. At the same level of true strain, the dislocation densities are comparable from room temperature up to $650^{\circ} \mathrm{C}$. However, at very high temperature $\left(800^{\circ} \mathrm{C}\right)$, dislocation density drops dramatically. According to the Ashby deformation mechanism map of austenitic steels[39], at a $2 \times 10^{-4} \mathrm{~s}^{-1}$ strain rate, the deformation mechanism turns from plastic deformation into power law creep at approximately $700^{\circ} \mathrm{C}$. Thus, the prominent decrease in dislocation density may originate from the activation of dislocation climb at this high temperature. The square root of dislocation densities were also compared with the true stress of the sample, as shown in Figure 11. The goodness of the linear fitting indicates the contribution of dislocations to work hardening. In 
addition, with the increase in temperature, both the intrinsic strength (intercept) and the shear modulus (slope) decrease, which is also consistent with the temperature effect on those material properties at high temperatures.

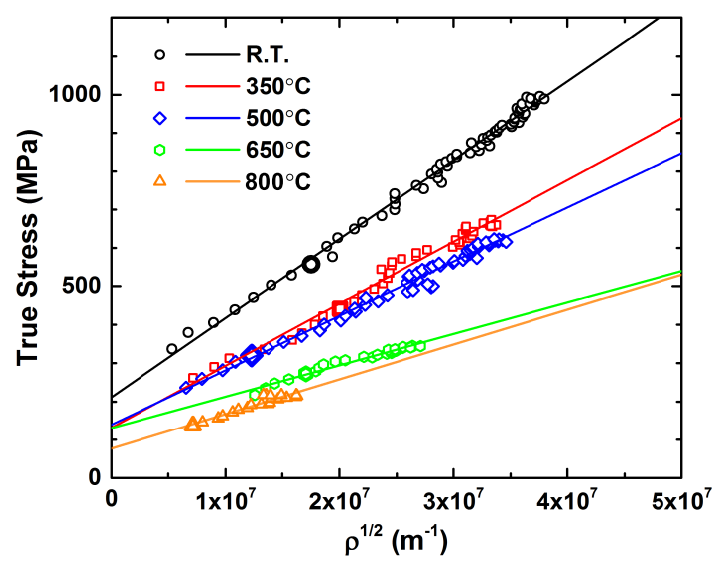

Figure 11: Dislocation strengthening indicated by the true stress vs. square root of dislocation density diagram: the data points closest to the yield stress values are highlighted by larger symbols.

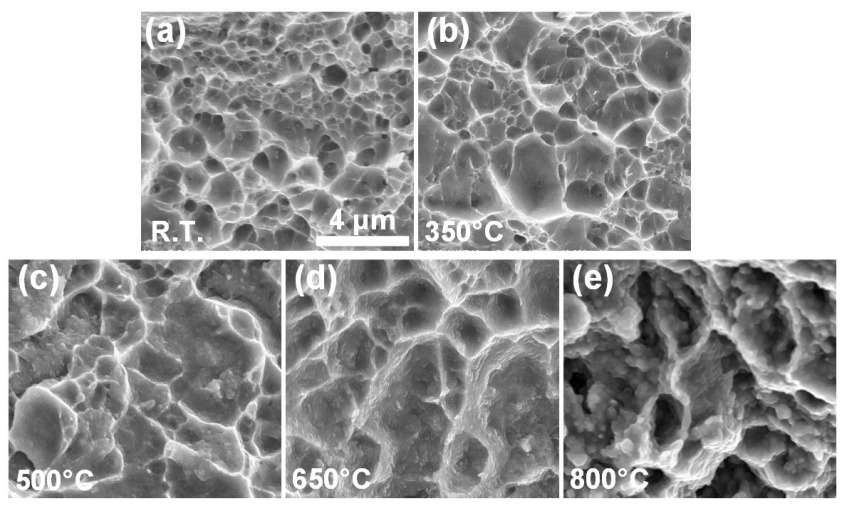

Figure 12: SEM images of the fracture surfaces of the tested tensile specimens.

At all testing temperatures, plastic dimples dominate the fracture surfaces, as illustrated in Figure 12. The dimples are supposed to be initiated by precipitates. However, due to the limited size of those precipitates, they are not identifiable in SEM images. As temperature increases, the 
dimple size tends to increase. This phenomenon implies that some precipitates stop contributing to the nucleation of fracture at elevated temperatures, which may be correlated to the fade of TiN's load partitioning. As the temperature exceeds $500^{\circ} \mathrm{C}$, severe oxidation on the fracture surface makes it challenging to look into microstructural details.

\section{Conclusions}

In this study, both synchrotron X-ray scattering and electron microscopy were utilized to characterize the precipitates within an ODS 310 austenitic stainless steel. A high density of uniformly distributed ultra-fine oxygen-enriched nanoparticles were found in this ODS 310 alloy. Further, an in situ synchrotron WAXS tensile investigation was performed at a variety of temperatures to explore the load partitioning phenomena of different types of precipitate phases through measuring the lattice strain evolution within the strained specimens. The extra lattice strain held by the conventional $\mathrm{MX}$ precipitates becomes marginal above $500^{\circ}$, implying a degradation in their load partitioning effect. Meanwhile, the strengthening effect due to the ultra-fine oxygen-enriched nanoparticles was maintained even at elevated temperatures up to $800^{\circ} \mathrm{C}$. This study revealed the strengthening mechanism of ODS alloy at both room and elevated temperature by investigating the microstructure evolution during plastic deformation, and emphasized the importance of developing practical ODS alloys for high temperature applications.

\section{Acknowledgments}

This work was supported by 973 DOE INL 120293. The TEM experiments were carried out in part at the Frederick Seitz Materials Research Laboratory Central Facilities, University of Illinois, which is partially supported by the U.S. Department of Energy (DOE) under Grants DEFG02-07ER46453 and DE-FG02-07ER46471. The author gratefully acknowledge the support of the International Institute for Carbon Neutral Energy Research (WPI-I2CNER), sponsored by the World Premier International Research Center Initiative (WPI), Minister of Education, Culture, Sports, Science and Technology (MEXT), Japan. The efforts involving Argonne National 
Laboratory were sponsored under Contract no. DE-AC02-06CH11357 between UChicago Argonne, LLC and the U.S. Department of Energy.

\section{References}

[1] S. Zinkle, G. Was, Acta Materialia 61 (2013) 735 - 758.

[2] S. Yamashita, S. Ohtsuka, N. Akasaka, S. Ukai, S. Ohnuki, Philosophical magazine letters 84 (2004) $525-529$.

[3] C. A. Williams, P. Unifantowicz, N. Baluc, G. D. Smith, E. A. Marquis, Acta Materialia 61 (2013) $2219-2235$.

[4] D. T. Hoelzer, J. Bentley, M. A. Sokolov, M. K. Miller, G. R. Odette, M. Alinger, Journal of Nuclear Materials 367 (2007) 166-172.

[5] K. Yutani, H. Kishimoto, R. Kasada, A. Kimura, J. Nucl. Mater. 367 (2007) 423-427.

[6] G. Odette, M. Alinger, B. Wirth, Annu. Rev. Mater. Res. 38 (2008) 471-503.

[7] M. S. El-Genk, J.-M. Tournier, Journal of Nuclear materials 340 (2005) 93-112.

[8] S. Ukai, S. Mizuta, M. Fujiwara, T. Okuda, T. Kobayashi, Journal of Nuclear Science and Technology 39 (2002) $778-788$.

[9] K. Mo, Z. Zhou, Y. Miao, D. Yun, H.-M. Tung, G. Zhang, W. Chen, J. Almer, J. F. Stubbins, Journal of Nuclear Materials 455 (2014) 376-381.

[10] T.-K. Kim, C.-S. Bae, D.-H. Kim, J.-S. Jang, S.-H. Kim, C.-B. Lee, D.-H. Hahn, Nuclear Engineering and Technology 40 (2008) 305-310.

[11] H. Oka, M. Watanabe, H. Kinoshita, T. Shibayama, N. Hashimoto, S. Ohnuki, S. Yamashita, S. Ohtsuka, Journal of Nuclear Materials 417 (2011) 279-282.

[12] M. Wang, Z. Zhou, H. Sun, H. Hu, S. Li, Mater. Sci. Eng. A 559 (2013) 287-292.

[13] Y. Miao, K. Mo, Z. Zhou, X. Liu, K.-C. Lan, G. Zhang, M. K. Miller, K. A. Powers, J. Almer, J. F. Stubbins, Materials Science and Engineering: A 625 (2015) 146-152.

[14] Y. Miao, K. Mo, Z. Zhou, X. Liu, K.-C. Lan, G. Zhang, M. K. Miller, K. A. Powers, Z.-G. Mei, J.-S. Park, et al., Materials Science and Engineering: A 639 (2015) 585-596.

[15] Y. Miao, K. Mo, B. Cui, W.-Y. Chen, M. K. Miller, K. A. Powers, V. McCreary, D. Gross, J. Almer, I. M. Robertson, et al., Materials Characterization 101 (2015) 136-143.

[16] K. Mo, D. Yun, Y. Miao, X. Liu, M. Pellin, J. Almer, J.-S. Park, J. F. Stubbins, S. Zhu, A. M. Yacout, Materials 9 (2016) 15 .

[17] X. Liu, K. Mo, Y. Miao, K.-C. Lan, G. Zhang, W.-Y. Chen, C. Tomchik, R. Seibert, J. Terry, J. F. Stubbins, Materials Science and Engineering: A 651 (2016) 55-62.

[18] Y. Miao, K. Mo, B. Ye, L. Jamison, Z.-G. Mei, J. Gan, B. Miller, J. Madden, J.-S. Park, J. Almer, et al., Scripta Materialia 114 (2016) 146-150.

[19] G. Zhang, Z. Zhou, K. Mo, P. Wang, Y. Miao, S. Li, M. Wang, X. Liu, M. Gong, J. Almer, et al., Journal of Alloys and Compounds 648 (2015) 223-228. 
[20] G. Zhang, K. Mo, Y. Miao, X. Liu, J. Almer, Z. Zhou, J. F. Stubbins, Materials Science and Engineering: A 637 (2015) 75-81.

[21] G. Zhang, Z. Zhou, K. Mo, Y. Miao, X. Liu, J. Almer, J. F. Stubbins, Journal of Nuclear Materials 467 (2015) $50-57$.

[22] M. R. Daymond, Journal of applied physics 96 (2004) 4263-4272.

[23] M. Daymond, P. Bouchard, Metallurgical and Materials Transactions A 37 (2006) 1863-1873.

[24] T. Ungár, in: Materials Science Forum, volume 278, Trans Tech Publ, pp. 151-157.

[25] T. Ungár, I. Dragomir, Á. Révész, A. Borbély, Journal of applied crystallography 32 (1999) 992-1002.

[26] J. Ilavsky, P. R. Jemian, Journal of Applied Crystallography 42 (2009) 347-353.

[27] G. Beaucage, Journal of Applied Crystallography 28 (1995) 717-728.

[28] J. Potton, G. Daniell, B. Rainford, Journal of Applied Crystallography 21 (1988) 663-668.

[29] P. Jemian, G. Long, F. Lofaj, S. Wiederhorn, in: MRS Proceedings, volume 590, Cambridge Univ Press, p. 131.

[30] K. R. Whittle, M. G. Blackford, R. D. Aughterson, G. R. Lumpkin, N. J. Zaluzec, Acta Materialia 59 (2011) $7530-7537$.

[31] Y. Miao, D. Aidhy, W.-Y. Chen, K. Mo, A. Oaks, D. Wolf, J. F. Stubbins, Journal of Nuclear Materials 445 (2014) 209-217.

[32] Y. Ohmori, Y. Maehara, Materials science and technology 2 (1986) 595-602.

[33] N. Nissley, M. Collins, G. Guaytima, J. Lippold, Welding in the World 46 (2002) 32-40.

[34] S. Mannan, K. Samuel, P. Rodriguez, Materials Science and Engineering 68 (1985) 143-149.

[35] AISI, High-Temperature Characterisitics of Stainless Steels, Technical Report, Nickel Development Institute, A designers Handbook Series No.9004.

[36] M. Zhang, J. He, Surface and Coatings Technology 142 (2001) 125-131.

[37] Y. Luan, Elastic properties of complex transition metal oxides studied by Resonant Ultrasound Spectroscopy, Ph.D thesis, The University of Tennessee, Knoxville, 2011.

[38] V. Valvoda, M. Järvinen, Powder Diffraction 5 (1990) 200-203.

[39] H. Frost, M. Ashby, in: Fundamental aspects of structural alloy design, Springer, 1977, pp. 27-65. 

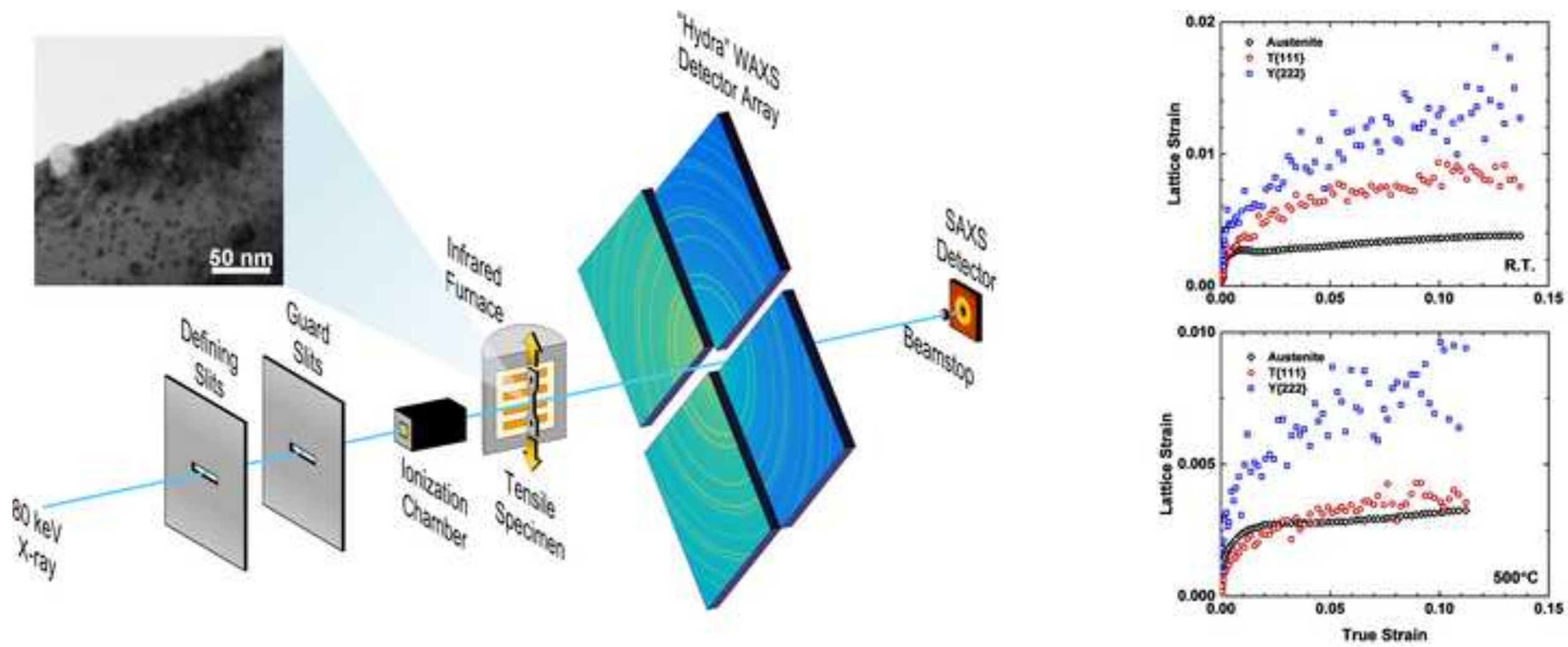